\title{
ATRIBUTOS FÍSICOS RELACIONADOS À COMPACTAÇÃO DE SOLOS SOB VEGETAÇÃO NATIVA EM REGIÃO DE ALTITUDE NO SUL DO BRASIL ${ }^{(1)}$
}

\author{
Rodrigo Vieira Luciano ${ }^{(2)}$,J ackson Adriano Albuquerque ${ }^{(3)}$, André da Costa ${ }^{(2)}$, Bruno \\ Batistella ${ }^{(4)} \&$ Maria Tereza Warmling ${ }^{(5)}$
}

\begin{abstract}
RESUMO
A compactação causada por atividades antrópicas altera os atri butos físicos do solo, causando redução na produtividade e impactos ao ambiente. Muitos estudos sobre esse tema têm sido realizados em solos agrícolas, porém poucas são as informações em áreas com vegetação nativa, nas quais, geralmente, os teores de matéria orgânica são mais elevados. Assim, é oportuno avaliar a relação entre os atributos físicos relacionados à compactação, nessas condições, a fim de estabelecer valores de referência para projetos de recuperação deáreas degradadas em campos naturais ou matas ciliares. Objetivou-se relacionar densidade máxima (DsMáx), umidade ótima de compactação (UOC) e densidade relativa (DR) com os limites de consistência, granulometria e teor de matéria orgânica de solos predomi nantes do Planalto Sul do Estado de Santa Catarina sob vegetação nativa de clima temperado. Amostras do horizonte A foram coletadas em dois Nitossolos, dois Neossolos e dois Cambissolos. Foram avaliados: a granulometria, a densidade de partícula, o teor de carbono orgânico total, os limites de liquidez, de plastici dade e de pegajosidade, 0 índice de plasticidade, a densidade máxi ma, a umidade ótima de compactação, a densidade do solo e a densidade relativa. A DsMáx aumenta com o teor de areia total e areia fina e reduz com os teores de argila e com os limites de liquidez e de pegajosidade. A UOC diminui nos solos arenosos, especialmente naqueles com predomi nância de areia fina, eaumenta nos argi losos ou com maior teor decarbono orgânico total e dos limites de Atterberg. A UOC variou entre 0,76 e 1,05 vezes 0 limite de plasticidade, tendo relação direta com o teor de silte, indicando que a umidade ótima de compactação não pode ser avaliada apenas com a determinação
\end{abstract}

\footnotetext{
(1) Recebido para publicação em 26 de outubro de 2011 e aprovado em 11 de outubro de 2012.

(2) Doutorando em Manejo do Solo, Departamento de Solos - DPS, Universidade do Estado de Santa Catarina, Centro de Ciências Agroveterinárias - UDESC - CAV. Bolsista do CNPq. Av. Luís de Camões, 2.090. Conta Dinheiro. CEP 88.520-000 Lages (SC). E-mail: agro.luciano@gmail.com, andrecosta.agro@hotmail.com

(3) Professor, DPS - UDESC - CAV. Pesquisador do CNPq. E-mail: albuquerque@pq.cnpq.br

(4) Acadêmico do curso de Agronomia, UDESC - CAV. E-mail: bruno.batistella@hotmail.com

(5) Mestranda em Manejo do Solo, DPS - UDESC - CAV. E-mail: tetecav@yahoo.com.br
} 


\begin{abstract}
do li mite de plasticidade de um solo. Os solos de altitude do Planalto Sul deSC têm relação UOC/LP diferente da de solos de outros locais, como consequência dos elevados teores de matéria orgânica desses solos.
\end{abstract}

\author{
Termos de indexação: ensaio de Proctor Normal, densidade relativa, limites de \\ consistência.
}

\author{
SUMMARY: PHYSICAL ATTRIBUTES RELATED TO SOIL COMPACTION \\ UNDER NATIVE VEGETATION OF SOUTHERN BRAZIL
}

\begin{abstract}
Thecompaction caused by anthropic activities alters thesoil physical properties, decreasing productivity and affecting theenvironment. Many studies on this topic havebeen conducted in agricultural soils; however thereis littl einformation in areas with nativevegetation, where, usually, organic matter levels are higher. Thus, it is essential to evaluate the relationship between physical properties related to compaction under theseconditions to establish reference values for therevegetation of nativegrassland or riparian forests. Theobjectivewas to relate maximum bulk density (MaxBD), optimum water content for compaction (OWC) and relative density (DR) with the limits of consistency, particle size and organic carbon content of predominant soils on the Southern Plateau of the State of Santa Catarina, Brazil, under nativevegetation of temperatedi mate Samples of A-H orizon werecoll lected from two Oxisols (Rhodicand Xanthic Kandiudox), two Entisols (LithicU dorthents and Typic U dipsamments) and two Inceptisols (Pachic Humudepts). Theparticlesizedistribution, particledensity, total organiccarbon content, limits of liquid, plasticity (LP) and stickiness, plasticity index, maximum bulk density (MaxBD), optimum water content (OWC) for compaction, bulk density, and the degree of compactness wereeval uated. The MaxBD increases in soils with higher sand and fine sand content, and decreases in soil s with higher day content and higher liquidity and stickiness limits. TheOWC decreases in sandy soils, especially thosewith a predominance of finesand, and increases in thosewith higher clay content, total organic carbon and Atterberg limits. The OWC was between 0.76 and 1.05 times thepl astic limit, directly related with thesilt content, indicating that theopti mum moisturecontent for compaction cannot bemeasured only by the determination of theplasticlimit of a soil. TheOWC/ LP ratio of soils at higher altitudein the Southern Plateau of Santa Catarina is different from that of soils in other places, as a consequence of thehigh levels of organic matter and silt in thesesoils.
\end{abstract}

Index terms: Standard Proctor test, relativebulk density, consistency limits.

\section{INTRODUÇÃO}

A compactação do sol o reduz a infiltração, aumenta o escoamento superficial deágua no solo, dificulta o crescimento dosistema radicular das plantas ereduz a absorção de nutrientes e, consequentemente, o rendimento das culturas.

O sol o pode estar naturalmente adensado ou, por meio de ação antrópica, compactado. O uso de máquinas e implementos com umidade do solo próxima ao limite de plasticidade é o principal fator que compacta os sol os agrícolas, pois a água reduz a coesão eatua como lubrificante entre as partículas de solo, permitindo o desl izamento e o empacotamento das partículas quando esteésubmetido a al gum tipo de pressão. Portanto, para manejar adequadamente os solos agrícolas e entender a dinâmica da compactação, é necessário avaliar os limites de Atterberg e sua relação com a densidade atual do solo, a densidade máxima de compactação e a umidade ótima de compactação, obtidos por meio do ensaio de Proctor Normal (Dias Júnior \& Miranda, 2000).

As classes de solos possuem comportamentos distintos quando submetidas à compactação, devido às variações da textura, da mineralogia, do teor de matéria orgânica, da umidade (Taylor \& Henderson, 1959; Silva et al., 1986; Stone \& Ekwue, 1993; Ekwue \& Stone, 1995, 1997), além do histórico de pressões promovido pel os processos pedogenéticos deformação epel o manejo do solo(DiasJ unior \& Pierce, 1996). De modogeral, a el evação dos teores deargila edematéria orgânica torna a curva de compactação platicúrtica, reduzindoa densidade máxima dosol oe aumentando a umi dade ótima de compactação (Silva et al., 1986; Ekwue\& Stone, 1997; Figueiredo et al., 2000; Braida et al., 2006; Marcolin \& Klein, 2011). I sso ocorre pelo fato de a argila e a matéria orgânica reterem mais água do que as frações siltee areia (Silva et al ., 1986), bem como pela baixa densi dade específica da matéria orgânica (Ekwue\& Stone, 1995). 
A densidade relativa (DR) édefinida comoa razão entrea densidade do solo nas condições de campo ea densi dademáxima do sol o obtida noensai o de Proctor N ormal. Alguns estudos sugerem que há uma faixa de DR mais adequada ao crescimento das culturas agrícolas. Carter (1990) obteve máximo rendimento decereais quando $\mathrm{DR}$ de sol os arenosos variou entre 0,77 e 0,84 , observando que o desenvolvimento das plantas diminuiu quando a DR foi maior que 0,89 , principalmente por deficiência de aeração do solo. Håkansson (1990), em estudo realizado em 100 campos experimentais abrangendo diferentes tipos de solos da Suécia, encontrou máximo rendimento de cevada (Hordeum vulgare L.) quando a DR estava próxima a 0,87. Lipiec et al. (1991) realizaram experimentos com cevada em um sol o com 0,20 e outro com $0,60 \mathrm{~kg} \mathrm{~kg}^{-1}$ de argila e concluíram que o crescimento das plantas e o rendimento de grãos são reduzidos quando a $\mathrm{DR}$ excede, respectivamente, 0,91 e 0,88, devido ao menor crescimento do sistema radicular das culturas no perfil e menor absorção de água e nutrientes pelas plantas. Em Latossolos Vermel hos de São Paulo, a soja produziu mais quando a DR estava próxima de 0,80 (Beutler et al., 2005). Suzuki et al. (2007) observaram, em um Latossolo Vermelho, maior rendimento da soja quando a DR estava próxima de 0,86, enquanto Reichert et al. (2009) constataram, em vários solos de clima subtropical, maior rendimento das culturas quandoa DR sesituava entre 0,80 e 0,90.

A maioria desses estudos foi realizada com o objetivo de avaliar a produvidade das culturas anuais em função do grau de compactação do solo. Por outrolado, estudos que avaliam DR em áreas com vegetação nativa são escassos. Essas informações são úteis no estabel ecimento deDR de referência na execução de projetos derecuper ação em áreas com solos degradados fisicamente, como as áreas de campo nativo ou matas ciliares, que estão sujeitas ao pisoteio excessivo de bovinos em sistemas extensivos de criação. Essetipo de uso do sol o é bastante comum no Planal to Sul do Estado deSanta Catarina (Benez, 2005). A densidade máxima ea DR desses sol os provavel mente diferem das daquel es observados em outras regi ões do Brasil, devido a uma condição diferenciada de clima nessa região em relação à grande parte do País, pois as temperaturas mais amenas em comparaçãoàs demais regiões de SC e do Brasil e o clima constantemente úmido (Pandolfo et al., 2002) favorecem maior acúmulo decarbono orgânicototal nosolo (Dalmolin et al., 2006).

Para um mesmo solo, variações da umidade modificam sensivel mentea sua consistência. Segundo Ojeniyi \& Dexter (1979), a umidade do solo que favorecea compactação pelas máquinas agrícolas está próxima a $90 \%$ do limite de plasticidade, o que também foi constatado por Figueiredo et al. (2000) em um Latossol o Roxo de M inas Gerais e por Braida et al. (2006) em um Nitossolo Vermel ho de Santa Catarina. Caso essa relação seja válida para qualquer tipo de solo, a determinação do limite de plasticidade pode ser utilizada para estimar a umidade ótima de compactação, dispensando a determinação do ensaio deProctor Normal, o qual necessita degrande volume de sol o e demanda maior tempo e equi pamentos mais caros para sua determinação, em comparação ao limite deplasticidade.

Objetivou-se neste estudo relacionar a densidade máxima (DsMáx), umidade ótima de compactação (UOC) e densidade relativa (DR) com os limites de consistência, granulometria eteor dematéria orgânica desol os predominantes do Planal to Sul do Estado de Santa Catarina sob vegetação nativa de clima temperado.

\section{MATERIAL E MÉTODOS}

O estudo foi realizado no Centro de Ciências Agroveterinárias (UDESC/CAV), em Lages/SC, com sol os representativos do Planal to Sul Catarinense. O clima na região édotipo Cfb, segundo classificação de Köppen (Pandolfo et al., 2002), ou seja, temperado, constantemente úmido, sem estação seca e com verão fresco (temperatura média do mês mais quente $<22,0^{\circ} \mathrm{C}$ ); a temperatura média normal anual varia de 13,8 a $15,8^{\circ} \mathrm{C}$; a média anual das temperaturas máximas varia de 19,4 a $22,3^{\circ} \mathrm{C}$, e a das temperaturas mínimas, de 9,2 a $10,8^{\circ} \mathrm{C}$. A média anual da precipitação pluvial total varia de 1.360 a $1.600 \mathrm{~mm}$, e a da umidade relativa do ar, de 80 a $83 \%$ (Benez, 2005).

A regiãodo PlanaltoSul Catarinense éconstituída por 19 municípios, distribuídos em uma área de $16.393 \mathrm{~km}^{2}$. Segundo informações contidas em Benez (2005), as classes de solos predominantes são Cambissolos (47\%), N eossolos Litólicos (43\%) e Nitossol os (9\%). Esses solos foram formados a partir de diferentes tipos de material de origem, altitudes (entre 825 e $1.350 \mathrm{~m}$ ) e demais fatores de formação do solo, oque determi na grandevariabilidade detextura, teor de matéria orgânica emineralogia.

Os sol os amostrados foram classificados, segundo - Sistema Brasileiro de Classificação de Solos (E mbrapa, 2006), em: Cambissol o Húmico al umínico típico (Pachic Humudepts), coletado em dois municípios $\left(\mathrm{CH}_{\text {Alu1 }}\right.$ e $\left.\mathrm{CH}_{\text {Alu2 }}\right)$; Nitossolo Vermelho alumínico húmico (Rhodic Kandiudox) $\left(\mathrm{NV}_{\mathrm{Alu}}\right)$; NitossoloBrunodistróficotípico (XanthicKandiudox) $\left(\mathrm{NB}_{\text {Dis }}\right)$; N eossolo Litólico húmico típico (Lithic Udorthents) ( $\mathrm{NL}_{\text {Hum }}$ ); e Neossol o L itólico distrófico típico (Tipic Udipsamments) ( $\left(\mathrm{L}_{\text {Dis }}\right)$. A geologia, litologia, uso atual elocal ização de cada perfil de sol o são apresentados no quadro 1.

Amostras de solo foram coletadas no centro da camada correspondenteao horizonte $A$ de cada classe desolo (5-10 cm). Para determinação da densidade do sol o (Ds) e da porosi dadetotal (PT), foram col etadas seis amostras com estrutura preservada, em anéis 
Quadro 1. Geologia, município, uso atual e localização dos seis solos do Planalto Sul Catarinense

\begin{tabular}{ccccccc}
\hline Solo & Formação geológica & Litologia & Município & Uso Atual & Latitude & Longitude \\
\hline $\mathrm{CH}_{\text {Alu1 }}$ & Rio do Rastro & Siltitos & Lages & Campo nativo & $27^{\circ} 44^{\prime} 22^{\prime \prime} \mathrm{S}$ & $50^{\circ} 20^{\prime} 9^{\prime \prime} \mathrm{W}$ \\
$\mathrm{CH}_{\text {Alu2 }}$ & Teresina & Folhelhos & Bom Retiro & Campo nativo & $27^{\circ} 48^{\prime} 55^{\prime \prime} \mathrm{S}$ & $49^{\circ} 32^{\prime} 37^{\prime \prime} \mathrm{W}$ \\
$\mathrm{NV}_{\text {Alu }}$ & Teresina & Folhelhos & Bom Retiro & Campo nativo & $27^{\circ} 43^{\prime} 53^{\prime \prime} \mathrm{S}$ & $49^{\circ} 47^{\prime} 18^{\prime \prime} \mathrm{W}$ \\
$\mathrm{NB}_{\text {Dis }}$ & Serra Geral & Basalto & Painel & Campo nativo & $27^{\circ} 53^{\prime} 42^{\prime \prime} \mathrm{S}$ & $50^{\circ} 7^{\prime} 45^{\prime \prime} \mathrm{W}$ \\
$\mathrm{NL}_{\text {Hum }}$ & Serra Geral & Basalto & São J oaquim & Campo nativo & $28^{\circ} 15^{\prime} 26^{\prime \prime} \mathrm{S}$ & $49^{\circ} 57^{\prime} 15^{\prime \prime} \mathrm{W}$ \\
$\mathrm{NL}_{\text {Dis }}$ & Botucatu & Arenito Botucatu & Ponte Alta & Floresta Nativa & $27^{\circ} 26^{\prime} 40^{\prime \prime} \mathrm{S}$ & $50^{\circ} 25^{\prime} 46^{\prime \prime} \mathrm{W}$ \\
\hline
\end{tabular}

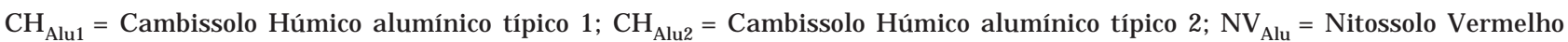
alumínico húmico; $\mathrm{NB}_{\mathrm{Dis}}=\mathrm{N}$ itossolo Bruno distrófico típico; $\mathrm{NL}_{\text {Hum }}=\mathrm{Neossolo} \mathrm{Litólico} \mathrm{húmico} \mathrm{típico;} \mathrm{NL}_{\mathrm{Dis}}=\mathrm{Neossolo}$ Litólico distrófico típico.

metálicos com volumede $70 \mathrm{~cm}^{3}(2,5 \mathrm{~cm}$ deal tura e 6 cm dediâmetro), deacordo com Embrapa (1997). Nas demais determinações, for am coletadas amostras com estrutura alterada, as quais foram secas ao ar e peneiradas em mal ha de $2,0 \mathrm{~mm}$ dediâmetro. O teor de carbonoorgânicototal (COT) foi determinadopel ométodo descrito em Tedescoet al. (1995); a granulometria, pelo método da pi peta (Gee\& Bauder, 1986), dividindo-seos teores deareia em duas dasses (areiafina-0,053-0,25 mm eareia grossa- 0,25-2,00 mm); ea densidadedepartícula (Dp), pelo método do balão volumétrico (Gubiani et al., 2006). As determinações deCOT, granulometria eDp foram realizadas em duplicata.

O limite deliquidez ( $L L$ ) foi determinado com a utilização do aparel ho de Casagrande, segundo Embrapa (1997), ecal culado pela equação: $L L=W_{N}(N /$ $25)^{0,12}$, em que LL é o limite de liquidez (g $100 \mathrm{~g}^{-1}$ ), representado pela umi dadegravimétrica ajustada para 25 rotações doaparel ho; $W_{N}$ éa umidadegravimétrica ( $g$ $100 \mathrm{~g}^{-1}$ ) correspondenteàs rotações da determinação; eN é o número de rotações da determinação. O limite de plasticidade(LP) foi determinadoem triplicata conforme descrito em Embrapa (1997), retirando-se $15 \mathrm{~g}$ da amostra desol o proveniente da determinação dolimite deliquidez eformando-seuma esfera, queécomprimida sobre placa de vidroatéformar um bastãocilíndrico de 3,0 mm de diâmetro, sem quebrar ou fluir. Nessa condição de plasticidade, os bastões de solo têm sua umidade gravimétrica determinada. O limite de pegajosidade ( $\mathrm{LPe}$ ) corresponde à percentagem de umi dade na qual o solo setornou aderente (E mbrapa, 1997). O LL, LP e LPe foram determinados em triplicata. $\mathrm{O}$ índice de plasticidade (IP) foi cal culado pela diferença entreoLL eoLP. O índicedeatividade deSkempton (Skempton, 1953) foi calculado pela razão entre o IP e o percentual da fração argila $(\%<2 \mu \mathrm{m})$ presentenas amostras desol oanal isadas. Utilizando o IP eoLL, os sol os foram dassificados segundooSistema UnificadodeClassificação deSol os (SUCS), desenvolvido por Casagrande(1948) eatualizado por Oliveira \& Brito (1998).

No ensaio de Proctor Normal foram utilizadas 12 amostras de solo, cada uma com 2,5 kg. As amostras foram secas ao ar e peneiradas em peneira com malha de 4,76 mm, sendo determinada a umidaderesidual. Elas foram umedecidas em interval os de $0,02 \mathrm{~kg} \mathrm{~kg}^{-1}$ para os solos com textura franca a argilosa e em interval os de $0,015 \mathrm{~kg} \mathrm{~kg}^{-1}$ para o solo com textura franco-arenosa. As amostras foram acondicionadas em sacos plásticos, onde permaneceram em repouso por $24 \mathrm{~h}$, para homogeneização da sua umidade. O ensaio de Proctor Normal foi realizado sem o reuso do material desolo, com duas repetições delabor atório em cada umidade testada por perfil de solo, em um aparel ho automático (Solotest ${ }^{\circledR}$ ), segundo ABNT (Associação Brasileira de Normas Técnicas), deacordo com a norma NBR 7.182 (ABNT, 1986). Após essas determinações, foi pl otado um gráfico com a umidade gravi métrica (variável independente) ea Ds (variável dependente), para cada classe de solo, conforme Stancati et al. (1981). F oram selecionadas apenas seis Ds, as quais contêm a densidade do solo máxima (DsMáx) e a umidade ótima de compactação(UOC), eliminando-se as umidades extremas, conforme procedimento recomendado pela norma NBR 7.182 (ABNT, 1986). Para cada sol ofoi ajustada uma equação polinomial de segundo grau. Noseu ponto demáxima obtém-se, na abscissa, a DsMáx e, na ordenada, a umidade ótima de compactação. A partir dessas determinações, foi calculada a densidaderelativa (DR), utilizando-se a equação DR =Ds(campo)/ DsMáx.

Na análise estatística, o coeficiente de correlação linear de Pearson foi calculado entre os limites de Atterberg ea granulometria do solo, oteor de COT ea densi dade de partículas etambém entre os atributos obtidos no ensaio de Proctor Normal (densidade máxima, umidadeótima e densi dade rel ativa) etodos os demais atributos físi cos do sol o avaliados.

\section{RESULTADOS E DISCUSSÃO}

\section{Granulometria e teor de car bono orgânico total}

Os teores de argila dos sol os variaram entre $126 \mathrm{e}$ $557 \mathrm{~g} \mathrm{~kg}^{-1}$, os de silte, entre 53 e $409 \mathrm{~g} \mathrm{~kg}^{-1}$, e os de areia, entre 98 e $821 \mathrm{~g} \mathrm{~kg}^{-1}$, o queresulta em variação nas dasses texturais desdefranco-arenosa atéargilosa 
Quadro 2. Granulometria, classe textural, teor de carbono orgânico total (COT) e densi dade de partícula (Dp) do horizonte A dos seis solos do Planalto Sul Catarinense

\begin{tabular}{|c|c|c|c|c|c|c|c|}
\hline Solo & Argila & Silte & Areia fina & Areia grossa & Classe Textural & СОт & Dp \\
\hline & \multicolumn{4}{|c|}{$-\mathrm{g} \mathrm{kg}^{-1}$} & & $\mathrm{~g} \mathrm{~kg}^{-1}$ & $\mathrm{~g} \mathrm{dm}^{-3}$ \\
\hline $\mathrm{CH}_{\text {Alu1 }}$ & 275 & 376 & 319 & 30 & Franco & 12 & 2,39 \\
\hline $\mathrm{CH}_{\text {Alu2 }}$ & 350 & 408 & 156 & 86 & Franco-argiloso & 42 & 2,21 \\
\hline $\mathrm{NV}_{\text {Alu }}$ & 371 & 409 & 157 & 63 & Franco-argiloso & 28 & 2,41 \\
\hline $\mathrm{NB}_{\text {Dis }}$ & 557 & 345 & 60 & 38 & Argila & 37 & 2,51 \\
\hline $\mathrm{NL}_{\mathrm{Hum}}$ & 517 & 377 & 47 & 60 & Argila & 89 & 2,13 \\
\hline $\mathrm{NL}_{\text {Dis }}$ & 126 & 53 & 529 & 292 & Franco-arenoso & 13 & 2,55 \\
\hline
\end{tabular}

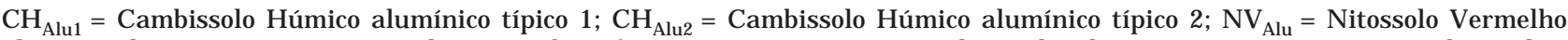
alumínico húmico; $\mathrm{NB}_{\mathrm{Dis}}=\mathrm{Nitossolo}$ Bruno distrófico típico ; $\mathrm{NL}_{\text {Hum }}=\mathrm{Neossolo} \mathrm{Litólico} \mathrm{húmico} \mathrm{típico;} \mathrm{NL}_{\mathrm{Dis}}=\mathrm{Neossolo}$ Litólico distrófico típico.

(Quadro2). A granulometria foi dependenteda litologia: osoloderivadodearenitoapresentou menor teor deargila; os derivados desiltitos/fol hel hos, teores intermediários deargila; eos derivados debasalto, teores deargila mais el evados. O teor decarbono orgânicototal (COT) variou de 12 a $89 \mathrm{~g} \mathrm{~kg}^{-1}$, sendo classificado como baixo no $\mathrm{CH}_{\text {Alu1 }}$ e no $\mathrm{NL}_{\text {Dis, }}$ médio no $\mathrm{NV}_{\text {Alu }}$ e al to em $\mathrm{NB}_{\text {Dis, }}$ $\mathrm{CH}_{\text {Alu2 }} \mathrm{eNL}_{\text {Hum }}$ (CQFS-RS/SC, 2004).

\section{Limites de consistência}

A grande amplitude nos teores de argila e COT influenciou oLL, que variou de 15 a $60 \mathrm{~g} 100 \mathrm{~g}^{-1}$, eo

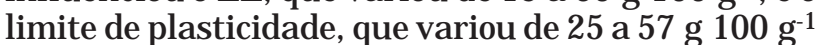
nos sol os plásticos. O NL $L_{\text {Dis }}$ não possui LP, devido à sua textura franco-arenosa. Os solos com maior LP foram aquel es com maior $L L$, porém com diferentes

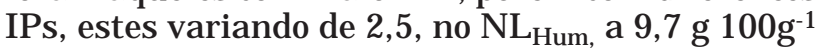
no $\mathrm{NB}_{\text {Dis }}$ (Quadro 3). Conforme a classificação sugerida por J enkins (Caputo, 1987), dos solos plásticos, o $\mathrm{NL}_{\text {Hum }}$ eoNV $\mathrm{Nlu}_{\text {são fracamente plásticos }}$ $(1<I P \leq 7)$, enquanto o $\mathrm{CH}_{\text {Alu2 }}, \mathrm{CH}_{\text {Alu1 }}$ e NB $\mathrm{Nis}_{\text {Dis }}$ são medianamente plásticos ( $7<1 \mathrm{P} \leq 15)$. Para oLPea

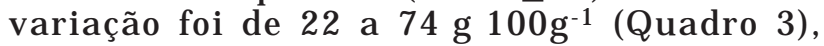
apresentando correlação positiva com os limites de liquidez e de plasticidade (Quadro 4).

Os limites de liquidez, plasticidade e pegajosidade aumentaram com oteor de argila e reduziram com os teores de areia total e areia fina. Apenas o LPe teve correlação positiva com oteor deCOT (Quadro 4). A Dp nãoalterou nenhum dosíndices deconsistêndia avaliados. Buckman \& Brady (1979) e Marcolin (2006) relataram correlação positiva entreoteor deargila eos limites de liquidez, de plasticidade eíndice de plasticidade. Nos sol os avaliados nãofoi observada correlação entreoteor de argila eo IP. Isso pode ser devido ao predomínio de argilominerais commenor superfícieespećfica, os quais diminuem a capacidade da fração argila de interagir com a água e reduzem o efeito lubrificante desta, não ocorrendo o deslizamento das partículas finas uma sobre as outras, o que reduz ol P do solo.

SegundoVargas (1993), para avaliar a consistência
Quadro 3. Limites físicos de plasticidade (LP), de liquidez (LL), de pegajosidade (LPe) e índices de consistência (IP) e atividade de Skempton (Ac) do horizonte A dos solos do Planalto Sul Catarinense

\begin{tabular}{|c|c|c|c|c|c|}
\hline Solo & LP & $\mathbf{L} \mathbf{L}$ & IP & LPe & Ac \\
\hline & \multicolumn{4}{|c|}{$\mathrm{g} 100 \mathrm{~g}^{-1}$} & \\
\hline $\mathrm{CH}_{\text {Alu1 }}$ & 25 & 32 & 7,2 & 36 & 0,26 \\
\hline $\mathrm{CH}_{\text {Alu2 }}$ & 32 & 40 & 7,2 & 43 & 0,21 \\
\hline $\mathrm{NV}_{\text {Alu }}$ & 39 & 44 & 5,7 & 48 & 0,15 \\
\hline $\mathrm{NB}_{\text {Dis }}$ & 45 & 54 & 9,7 & 58 & 0,17 \\
\hline $\mathrm{NL}_{\text {Hum }}$ & 57 & 60 & 2,5 & 74 & 0,05 \\
\hline $\mathrm{NL}_{\text {Dis }}$ & $N P$ & 15 & - & 22 & - \\
\hline
\end{tabular}

$\mathrm{CH}_{\text {Alu1 }}=$ Cambissolo Húmico alumínico típico $1 ; \mathrm{CH}_{\text {Alu2 }}=$ Cambissolo Húmico alumínico típico 2; $\mathrm{NV}_{\mathrm{Alu}}=$ Nitossolo Vermelho alumínico húmico; $\mathrm{NB}_{\text {Dis }}=$ Nitossolo Bruno distrófico típico; $\mathrm{NL}_{\text {Hum }}=\mathrm{N}$ eossol o Litól ico húmico típico; $\mathrm{NL}_{\mathrm{Dis}}=\mathrm{N}$ eossolo Litólico distrófico típico. NP = não plástico.

dosoloéindispensável fazer uma análise comparativa desua plasticidade, que pode ser real izada por meio da carta de plastici dadeem conjunto com o gráfico de atividade de Skempton. Observando-sea posição de cada sol o na carta de plasticidade (F igura la), oNL $L_{\text {Dis }}$ podeser classificado como "sol o sem coesão"; o CH $\mathrm{CH}_{\text {Alu1 }}$, $\mathrm{CH}_{\text {Alu2 }}$ e $\mathrm{NV}_{\text {Alu, }}$ como "siltes inorgânicos de baixa compressibilidade"; e o NL $\mathrm{H}_{\text {Hum }}$ e NB $\mathrm{B}_{\text {Dis, }}$ como "siltes inorgâni cos dealta compressibilidade".

A classificação dos sol os utilizando a atividade de Skempton (Ac) variou em função da litologia deles (Quadro 3). Observa-se que todos os solos estão situados abaixo da linha de atividade 0,75, e a dassificação da fração fina dos sol os é “argilominerais inativos" (F igura 1b). Essa classificação indica que, no Planal to Catarinense, o horizonte $A$ dos solos tem índice de plasticidade baixo, em função dos fatores e processos de formação do solo, que favorecem a formação de argilominerais do tipo 1:1 (caulinita) e 
menor quantidade do tipo 2:1:1 (argilas 2:1 com hidróxido entrecamadas), além de pequena presença deóxidos deFe, predominantementegoethita (Almeida \& Kämpf, 1997), etambém devido aos el evados teores de COT do solo, pois este atributo correlacionou-se negativamente com a atividade de Skempton (Ac) (Quadro4).

\section{Densidade máxima, umidade ótima para compactação e densi dade do solo}

A densidade máxima variou de 1,02 a $1,81 \mathrm{~g} \mathrm{~cm}^{-3}$, ea umidadeótima de compactação, de 0,14 a $0,48 \mathrm{~g} \mathrm{~g}^{-1}$ (Figura 2). A DsMáx decresceu na seguinte ordem: $\mathrm{NL}_{\text {Dis }}>\mathrm{CH}_{\text {Alu1 }}>\mathrm{NB}_{\text {Dis }}>\mathrm{CH}_{\text {Alu2 }}>\mathrm{NV}_{\text {Alu }}>\mathrm{NL}_{\text {Hum, }}$ ea UOC de compactação, na ordem a seguir: $N L_{\text {Dis }}<$ $\mathrm{CH}_{\text {Alu1 } 1}<\mathrm{NB}_{\text {Dis }}=\mathrm{CH}_{\text {Alu2 }}<\mathrm{NV}_{\text {Alu }}<\mathrm{NL}_{\text {Hum. }}$. A Ds no horizonte $A$ dos sol os mantidos com vegetação nativa variou entre 0,78 e 1,40 $\mathrm{g} \mathrm{cm}^{-3}$ (Figura 3).

A elevada amplitudenas DsMáx, UOC eDs mostra a importância de estudar diferentes tipos de sol o que ocorrem em uma região a fim de estabel ecer val ores de referência para esses atributos físicos. Observa-se que cada tipo de solo tem uma Ds, DsMáx e UOC específica, e a utilização desses val ores para outras classes de sol o podelevar a grandes erros na definição da umidadeideal de manejo ou da avaliação do estado atual de compactação de uma determinada área.

Para entender por que os atributos estudados variaram, foi realizada análise decorrelaçãoentreeles e as frações granul ométricas e o teor de COT. H ouve correl ação entre a DsMáx ea UOC com os teores de

Quadro 4. Coeficiente de correlação de Pearson entre os limites eíndices de consi stência com a granul ometria, teor de car bono orgânico total (COT) e densidade de partículas (Dp) do horizonte A dos solos do Planalto Sul Catarinense

\begin{tabular}{lccccc}
\hline Atributo & $\mathbf{L P}$ & $\mathbf{L L}$ & $\mathbf{I P}$ & $\mathbf{L P e}$ & $\mathbf{A C}$ \\
\hline LL & $0,98^{* *}$ & - & & & \\
IP & $-0,53$ & $-0,35$ & - & & \\
LPe & $0,99^{* *}$ & $0,97^{* *}$ & $-0,54$ & - & \\
AC & $-0,96^{* *}$ & $-0,90^{*}$ & 0,71 & $-0,95^{*}$ & - \\
Argila & 0,87 & $0,98^{* *}$ & $-0,05$ & $0,93^{* *}$ & $-0,72$ \\
Silte & $-0,31$ & 0,73 & $-0,36$ & 0,62 & 0,08 \\
Areia total & $-0,91^{*}$ & $-0,95^{* *}$ & 0,15 & $-0,86^{*}$ & 0,80 \\
Areia fina & $-0,90^{*}$ & $-0,98^{* *}$ & 0,20 & $-0,91^{*}$ & 0,81 \\
Areia grossa & 0,12 & $-0,76$ & $-0,32$ & $-0,65$ & $-0,25$ \\
COT & $0,89^{*}$ & 0,78 & $-0,70$ & $0,89^{*}$ & $-0,89^{*}$ \\
Dp & $-0,35$ & $-0,54$ & 0,77 & $-0,61$ & 0,47 \\
\hline
\end{tabular}

LL: limite de liquidez, LP: limite de plasticidade, IP: índice de plasticidade, LPe: limite de pegajosidade, Ac: atividade de Skempton, Teste $\mathrm{H}_{0}$ : $|\mathrm{r}|$ = zero, quando ${ }^{*}=$ significativo $(0,01<p<0,05) e^{* *}=$ significativo $(p<0,01)$.
COT (Figura 4) e com as frações granulométricas (Quadro5), especialmente com os teores de areia fina e argila (Figura 5). A variação na DsMáx foi maior nos sol os com menor teor deCOT (entre $12 \mathrm{e} 40 \mathrm{~g} \mathrm{~kg}^{-1}$ ), sendo ajustada por uma equação polinomial inversa de primeiro grau (Figura 4a). Figueiredo et al . (2000) e Braida et al. (2006) também relataram reduções lineares da DsMáx com o aumento do teor de COT do solo. Segundo esses autores, a densidade da matéria orgânica ( $\pm 1 \mathrm{~g} \mathrm{~cm}^{-3}$ ) é menor do quea densidade dos demais constituintes minerais do solo $\left( \pm 2,6 \mathrm{~g} \mathrm{~cm}^{-3}\right)$, resultando na redução da Ds e da DsMáx com o aumento do teor de matéria orgânica (Braida et al., 2006). Além disso, a matéria orgânica é um constituintequefavorece a estruturação (Baumgartl \& Horn, 1991).

Por outro lado, a UOC aumentou com o teor de COT do solo (Figura 4b), o que é atribuído à alta capacidade de retenção deágua da matéria orgânica

(a)
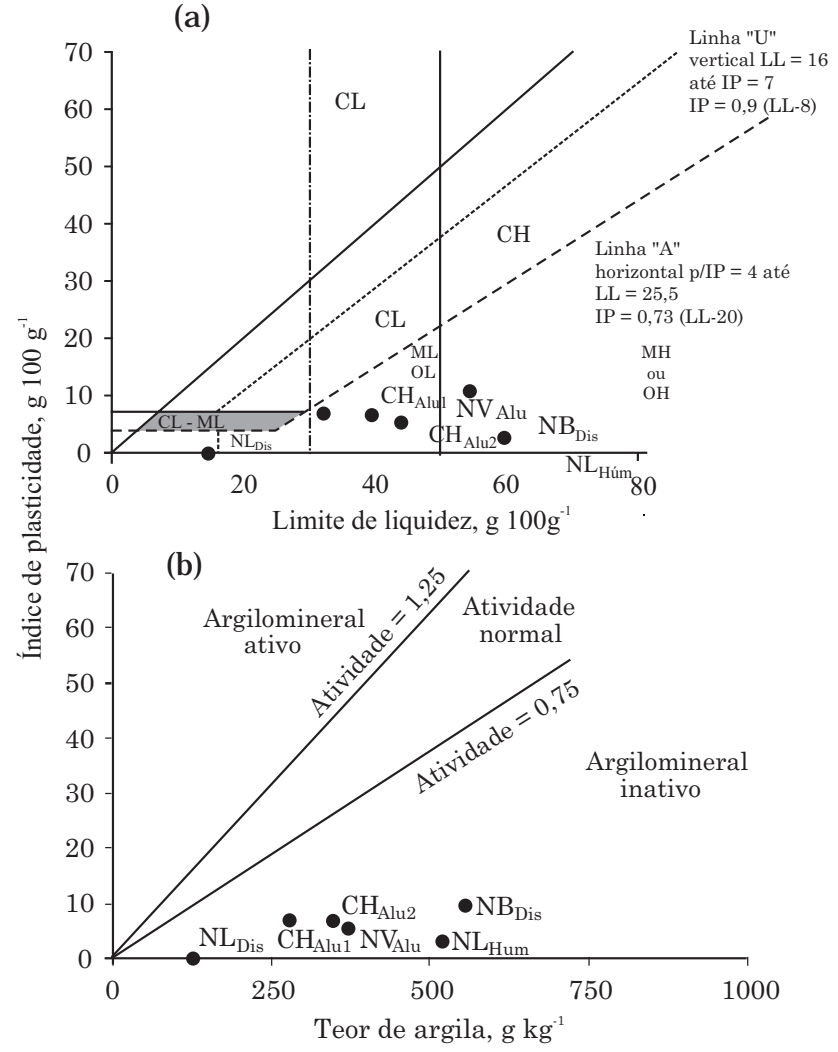

Figura 1. Carta de plasticidade (a) e atividade de Skempton (b) para o horizonte A de seis solos do Planalto Sul Catarinense. $\mathrm{CH}_{\mathrm{Alu1}}$ : $\mathrm{Cambissolo}$ Húmico alumínico 1; $\mathrm{CH}_{\mathrm{Alu2}}$ : Cambissolo Húmico alumínico 2; $\mathrm{NV}_{\text {Alu }}$ : Nitossolo Vermelho alumínico; NB Dis: Nitossolo Bruno distrófico; $\mathrm{NL}_{\text {Hum: }}$ NeossoloLitólico húmico, $\mathrm{NL}_{\text {Dis: }}$ Neossolo Litólico distrófico. * NL Dis: solo sem coesão (IP =zero); ** Classificação da fração fina do solo pela SUCS (ASTM, 2008): C: argila; M: silte; O: orgânico; L: baixa compressibilidade; $\mathrm{H}$ : alta compressibilidade. 
(Silva et al., 1986). Nos solos com maior teor deCOT énecessáriomais água para diminuir a coesãoe oatrito internoentreas partículas epromover sua "lubrificação" (Hillel, 1998) e, assim, permitir o cisalhamento dos agregados e a deformação plástica dosolo.

Nos solos com maior teor de areia fina, a DsMáx

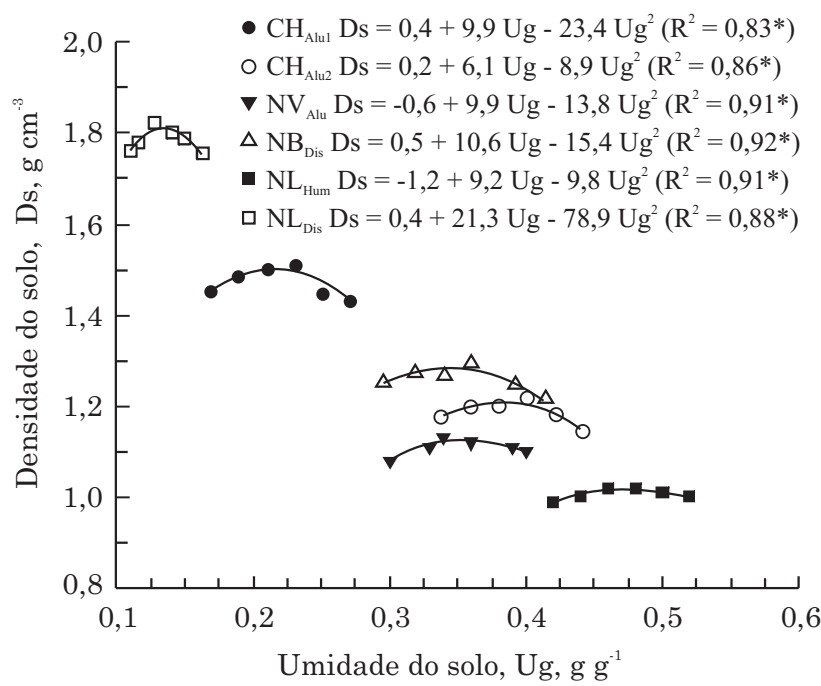

Figura 2. Curvas de compactação do horizonte A de seis solos do Planalto Sul Catarinense pelo ensaio de Proctor Normal. $\mathrm{CH}_{\text {Alu1: }}$ Cambissolo Húmico alumínico 1; $\mathrm{CH}_{\mathrm{Alu2}}$ : Cambissolo Húmico alumínico 2; $\mathbf{N V}_{\text {Alu: }}$ Nitossolo Vermelho

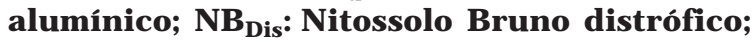
$\mathrm{NL}_{\text {Hum: }}$ Neossolo Litólico húmico, $\mathrm{NL}_{\text {Dis: }}$ Neossolo Litólico distrófico. *: significativo $(0,01<p<0,05)$ $e^{* *}$ : significativo $(p<0,01)$ pelo teste $F$.

(a)

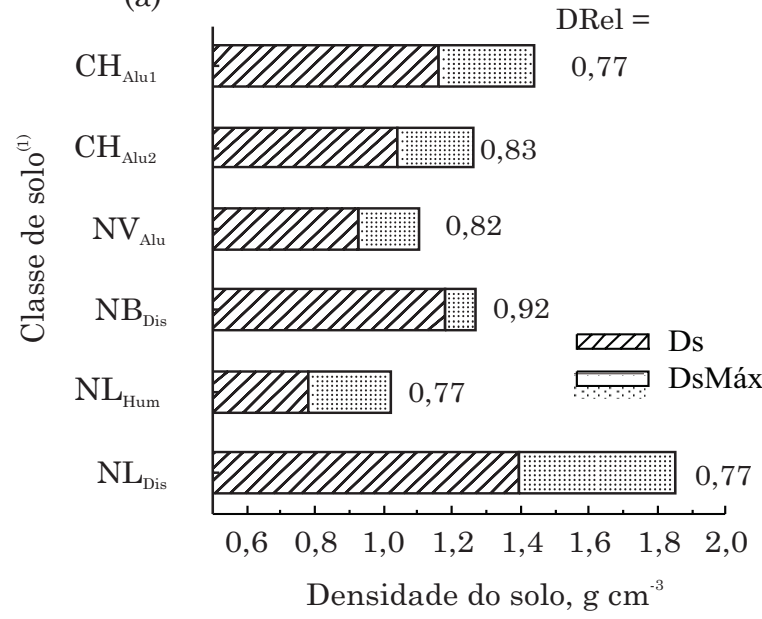

aumentou até $1,81 \mathrm{~g} \mathrm{~cm}^{-3}$ e a UOC diminuiu até próximo de 0,15 $\mathrm{g} \mathrm{g}^{-1}$ (Figura 4c,d), devido ao mel hor arranjamento/empacotamento das partículas da fração da areia fina em relação às frações com maior diâmetro de partículas. Contrariamente ao efeito da areia, o acréscimo doteor de argila reduziu a DsMáx e elevou a UOC (Figura 4e,f), fatotambém constatado por Dias J unior \& Miranda (2000) eF iguei redo et al . (2000). O efeito do teor deargila sobre a DsMáx ea UOC pode ser observadoao secomparar o $\mathrm{CH}_{\mathrm{Alu} 1}$ com oNL $\mathrm{Dis}_{\text {Dis }}$ os quais têm omesmoteor de COT. O CH $\mathrm{Clu}_{\text {Alu }}$ apresentou menor DsMáx emaior UOC em razãodo seu maior teor argila. A influência doteor deargila sobreesses atributos ocorre pela maior quantidade decargas desuperfíciee área superficial específica (Meurer et al., 2000), características que, somadas à maior capilaridadedos solos argi losos, resultam em maior retenção de água, em comparação aos solos com maior teor de silte e, ou, areia (Hillel, 1998; Reichert et al., 2009).

As diferenças na granulometria do solo, especialmente no teor de areia fina e de argila, auxiliam a entender porquea DsMáx ea UOC variam entre os solos e mesmo dentro de solos da mesma classe. Assim, a variação na DsMáx e na UOC entre os dois Cambissol os Húmi cos eentre os dois Neossolos Litóli cos podeestar associada aos teores deareia fina, argila eCOT. O menor teor deCOT (Figura $4 a, b)$ e de argila (Figura $4 \mathrm{e}, \mathrm{f}$ ) do $\mathrm{CH}_{\text {Alu1 }}$ em relação ao $\mathrm{CH}_{\text {Alu2 }}$, e do $N L_{\text {Dis }}$ em relação ao $\mathrm{NL}_{\text {Hum, }}$, resultou em maior DsMáx e menor UOC. Entretanto, essa constatação não é válida para os Nitossolos, pois, ao analisar os teores de argila eCOT, houve tendência inversa em comparação aos Cambissol os e Neossol os, visto queo $\mathrm{NB}_{\text {Dis }}$ possui maior teor de argila e de COT e teve maior DsMáxeUOC semelhanteaoNV $\mathrm{Nlu}_{\text {. Nessecaso, }}$ (b)

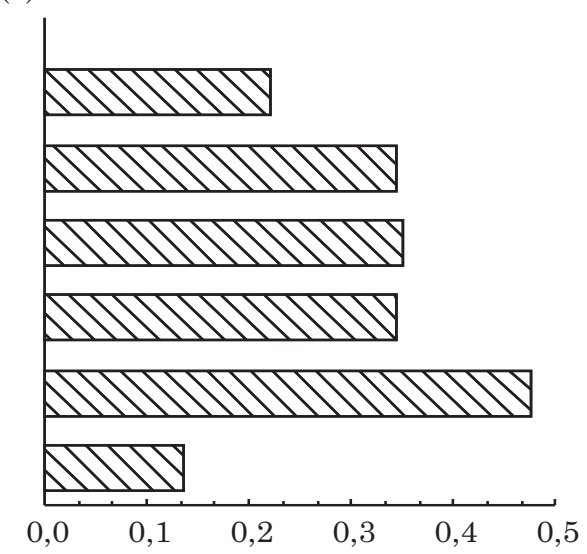

Umidade ótima de compactação, UOC, g g

Figura 3. Densidade do solo (Ds), densidade máxima (DsMáx), densidade relativa (DRel) (a) e umidade ótima de compactação (UOC) (b) do horizonte A de seis solos do Planalto Sul Catarinense. (1) $\mathrm{CH}_{\text {Alu1: }}$ Cambissolo Húmico alumínico 1; $\mathrm{CH}_{\mathrm{Alu} 2 \text { : }}$ Cambissolo Húmico alumínico 2; $\mathrm{NV}_{\mathrm{Alu}}$ : Nitossolo Vermelho alumínico; $\mathrm{NB}_{\text {Dis: }}$ Nitossolo Bruno distrófico; $\mathrm{NL}_{\mathrm{Hum}}$ : Neossolo Litólico húmico, $\mathrm{NL}_{\text {Dis: }}$ Neossolo Litólico distrófico. 
(a)

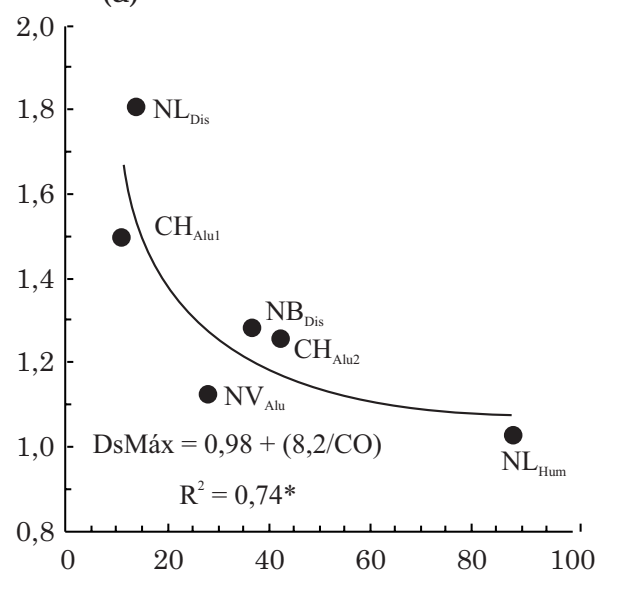

(b)

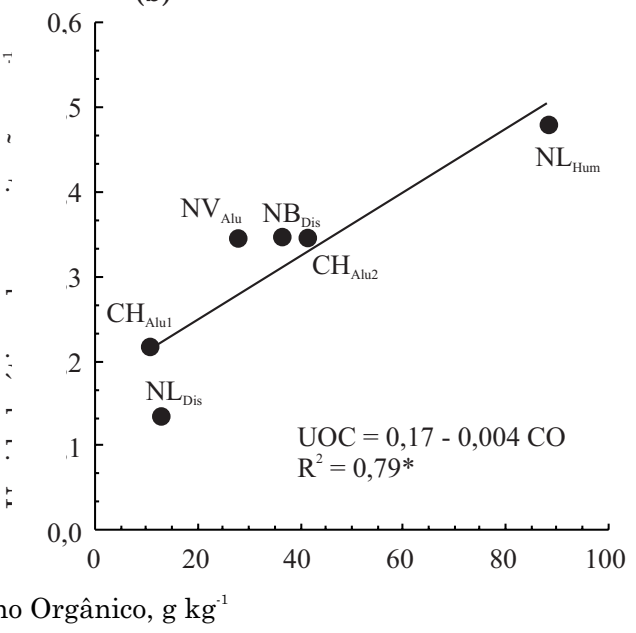

(c)

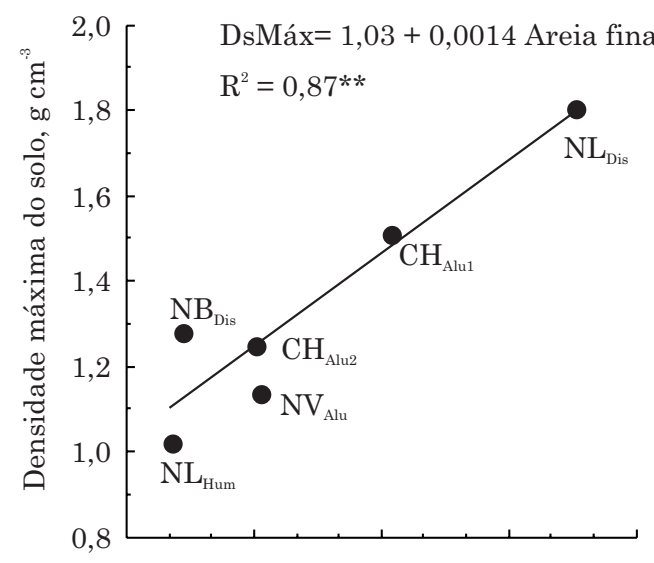

(d)

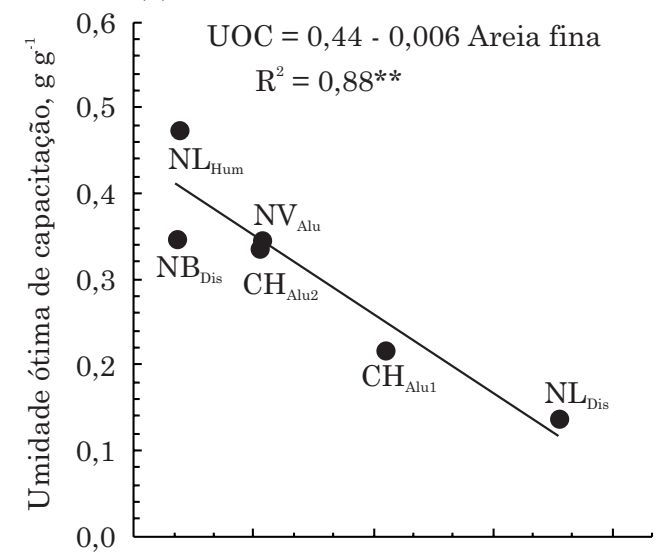

Teor de areia fina, $\mathrm{g} \mathrm{kg}^{-1}$

(e)

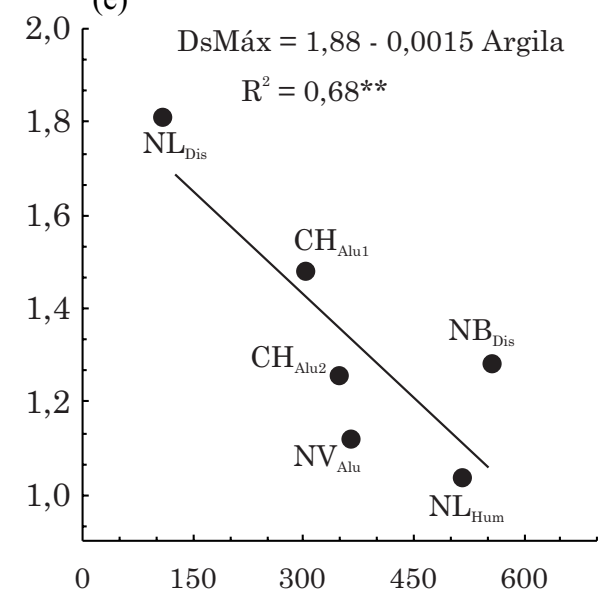

(f)

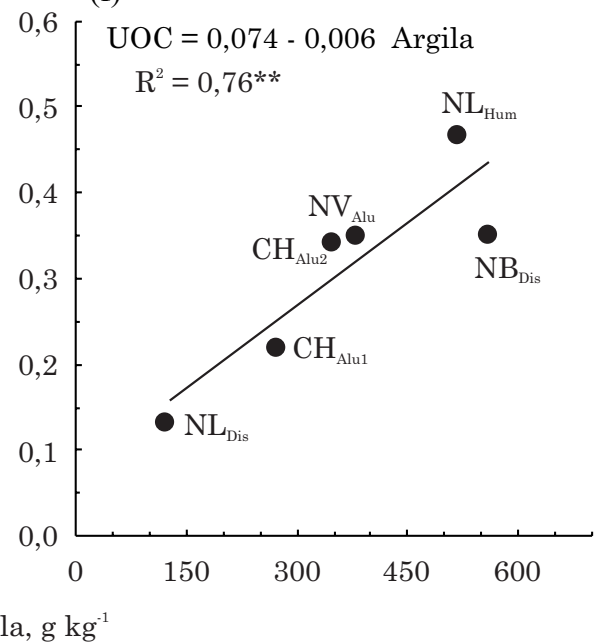

Figura 4. R elação entre o teor de carbono total e a densi dade máxima (a) umidade ótima de compactação (b), entre densidade máxi ma e os teores de areia fina (c) e argila (e) e a relação entre umidade ótima de compactação e os teores de areia fina (d) e argila (f) no horizonte A de seis solos do Planalto Sul Catarinense. $\mathrm{CH}_{\mathrm{Alu1}}$ : Cambissolo Húmico alumínico 1; $\mathrm{CH}_{\mathrm{Alu2}}$ : Cambissolo Húmico alumínico 2; $\mathrm{NV}_{\text {Alu: }}$ : Nitossolo Vermelho alumínico; $\mathbf{N B}_{\text {Dis: }}$ Nitossolo Bruno distrófico; $\mathbf{N L}_{\text {Hum: }}$ Neossolo Litólico

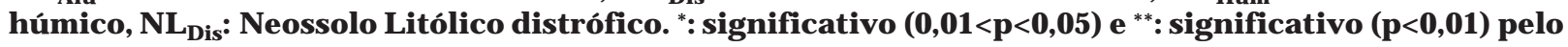
teste F. 
a diferença entreos dois sol os pode estar associada às diferenças na Dp, mineral ogia e agregação.

A densidade de cada solo no ambiente natural variou de 0,78 no $\mathrm{NL}_{\text {Hum }}$ a $1,40 \mathrm{~g} \mathrm{~cm}^{-3}$ no $\mathrm{NL}_{\text {Dis }}$ (Figura 3a). Os solos com maiores densidade foram os que apresentaram, também, as maiores DsMáx e as menores UOC, resultado do efeito direto da granulometria do sol o sobre essas variáveis, ondesolos com maior teor deareia possuem maior Ds, DsMáxe menor UOC (Quadro5).

A densidade relativa (DR) foi menor no $\mathrm{CH}_{\text {Alu1 }}$, $\mathrm{NL}_{\text {Dis }}$ e $\mathrm{NL}_{\text {Hum }}$, intermediária no $\mathrm{NV}_{\text {Alu }}$ e $\mathrm{CH}_{\text {Alu2 } 2} \mathrm{e}$ maior no NB $B_{\text {Dis }}$ (Figura 3a). ConformeCarter (1990), Lipiec et al. (1991), Suzuki et al. (2007) e Reichert et al. (2009), DR maiores que 0,80, 0,86, 0,88, 0,89 e 0,91 , respectivamente, seriam críticas para os sol os estudados, pois restringiriam o crescimento radicular das plantas cultivadas para produção de grãos. No $\mathrm{CH}_{\text {Alu1 } 1}, \mathrm{NL}_{\text {Dis }}, \mathrm{NL}_{\text {Hum }} \mathrm{NV}_{\text {Alu }}$ e $\mathrm{CH}_{\text {Alu2 }}$ foram encontradas DRs menores que 0,82 , o que indica ausência de limitação para a implantação de culturas anuais, considerando a substituição do campo nativo para a implantação de lavouras comerciais sem o revolvimento do sol o. O único sol o com $D R$ acima da densidade crítica ( $D R=0,92 ;$ Figura 3 ) foi o $\mathrm{NB}_{\text {Dis, }} \mathrm{O}$ queindica quea DR está acima dos valores relatados como críticos para cultivos anuais eocorreria limitação do crescimento dessas plantas caso esse solo fosse utilizado para a produção de grãos, sem um revolvimento prévio. Todavia, ainda não existem estudos que indiquem DRs críticas para solos sob vegetação decamponativo ou floresta nativa que foram submetidos a al gum processo de compactação, como pisoteio animal ou tráfego de máquinas. A área de coleta das amostras era pastejada por bovinos de corte em sistema extensivo de criação, porém não foram observados sintomas de limitação de crescimento do campo nativo no local de coleta, o que indica que esse tipo de vegetação consegue se desenvolver em solos com DR maior que 0,90 .

Diferentemente da DsMáx e da UOC, não houve relação entre a DR com os teores de COT ou com as frações granulométricas do solo (Quadro 5). Essa constataçãofoi importante, pois reforça o potencial de uso da DR como indicador de qualidade do solo, independentementeda sua dassetextural (Håkansson \& Lipiec, 2000), ao contrário da avaliação isolada da densidadedo solo, pois esta éintimamenterelacionada à granulometria do solo (Reichert et al., 2009; Keller \& Håkansson, 2010) e ao teor de carbono orgânico (Braida et al., 2010).

\section{Relações da densidade máxima, umidade óti ma de compactação e densi dade relativa com os limites de consistência do solo}

A DsMáx foi menor ea U OC maior nos solos com maiores LPs, LPes eLLs (Quadro 5), enquantoa DR teve relação apenas com oIP. A Ds correlacionou-se negativamente com o LP (Quadro 5 e Figura 5) e positivamente com o IP (Quadro 5). A causa das correlações observadas entre os atributos do ensaio de Proctor Normal e os limites de consistência é, provavelmente, o efeito direto das frações granul ométricas do sol o sobre essas variáveis, pois o teor deareia total dosolo, por exemplo, tevecoeficiente

Quadro 5. Coeficiente de correlação de Pearson entre os parâmetros obtidos no ensaio de Proctor e alguns atri butos físicos do horizonte A de seis solos do Planalto Sul Catarinense

\begin{tabular}{|c|c|c|c|c|c|}
\hline \multirow{2}{*}{ Atributos } & \multirow{2}{*}{ Umidade ótima } & \multicolumn{3}{|c|}{ Densidade } & \multirow{2}{*}{ Relação UOC/LP } \\
\hline & & Máxima & Relativa & Do solo & \\
\hline Densidade máxima & $-0,97 * *(1)$ & & & & \\
\hline Densidade relativa & 0,21 & $-0,22$ & & & \\
\hline Densidade do solo & $-0,91 *$ & $0,94 * *$ & 0,12 & & \\
\hline Relação UOC/LP & 0,69 & $-0,80$ & 0,29 & $-0,72$ & \\
\hline Argila & $0,87 *$ & $-0,82 *$ & 0,56 & $-0,64$ & $-0,57$ \\
\hline Silte & 0,72 & $-0,83^{*}$ & 0,27 & $-0,76$ & $0,90 *$ \\
\hline Areia total & $-0,88^{*}$ & $0,91 *$ & $-0,47$ & 0,77 & 0,42 \\
\hline Areia fina & $-0,94 * *$ & $0,93 * *$ & $-0,50$ & 0,78 & 0,24 \\
\hline Areia grossa & $-0,65$ & 0,74 & $-0,36$ & 0,64 & 0,84 \\
\hline Carbono orgânico & $0,89 *$ & $-0,76$ & $-0,06$ & $-0,78$ & $-0,13$ \\
\hline Densidade de partícula & $-0,73$ & 0,68 & 0,32 & 0,81 & $-0,40$ \\
\hline Limite de plasticidade & $0,93^{*}$ & $-0,84$ & 0,03 & $-0,67$ & $-0,43$ \\
\hline Limite de liquidez & $0,94 * *$ & $-0,92 *$ & 0,40 & $-0,79$ & $-0,49$ \\
\hline Índice de plasticidade & $-0,64$ & 0,68 & $0,80 *$ & $0,94 *$ & $-0,07$ \\
\hline Limite de pegajosidade & $0,95 * *$ & $-0,89 *$ & 0,23 & $-0,82^{*}$ & $-0,46$ \\
\hline Atividade da argila & $-0,95 *$ & $0,93^{*}$ & 0,16 & 0,84 & 0,27 \\
\hline
\end{tabular}

${ }^{(1)}$ Teste $\mathrm{H}_{0}:|r|=$ zero, quando ${ }^{*}=$ significativo $(0,01<p<0,05) \mathrm{e}^{* *}=$ significativo $(\mathrm{p}<0,01)$ pelo teste $\mathrm{F}$; UOC/LP=relação entre a umidade ótima de compactação e o limite de plasticidade; 
de correlação muito parecido (em valor absoluto) com o de LP, LPe, LL, DsMáx e UOC (Quadros 4 e 5).

A relação UOC/LP variou de 0,76 a 1,05 para os cinco solos plásticos (Figura 6a), aumentando com o teor de silte no solo (Figura 6b). Alguns estudos, como os realizados por Ojeniyi \& Dexter (1979), Figueiredo et al. (2000) e Braida et al. (2006), obtiveram um valor fixo de 0,90 para a relação $\mathrm{UOC} / \mathrm{LP}$, enquanto Marcolin (2006) obteve um modelo polinomial de segundo grau entre a relação UOC/LP e o teor de argila do solo, com variação de 0,85 a 1,20. Neste estudo, obteve-se a equação de regressão linear UOC/ $\mathrm{LP}=-0,58+0,004$ silte $\left(\mathrm{R}^{2}=0,80^{*}\right)$, sendo o silte expresso em $\mathrm{g} \mathrm{kg}{ }^{-1}$. Observa-se que os solos de altitude do Planalto Sul de SC têm relação UOC/LP
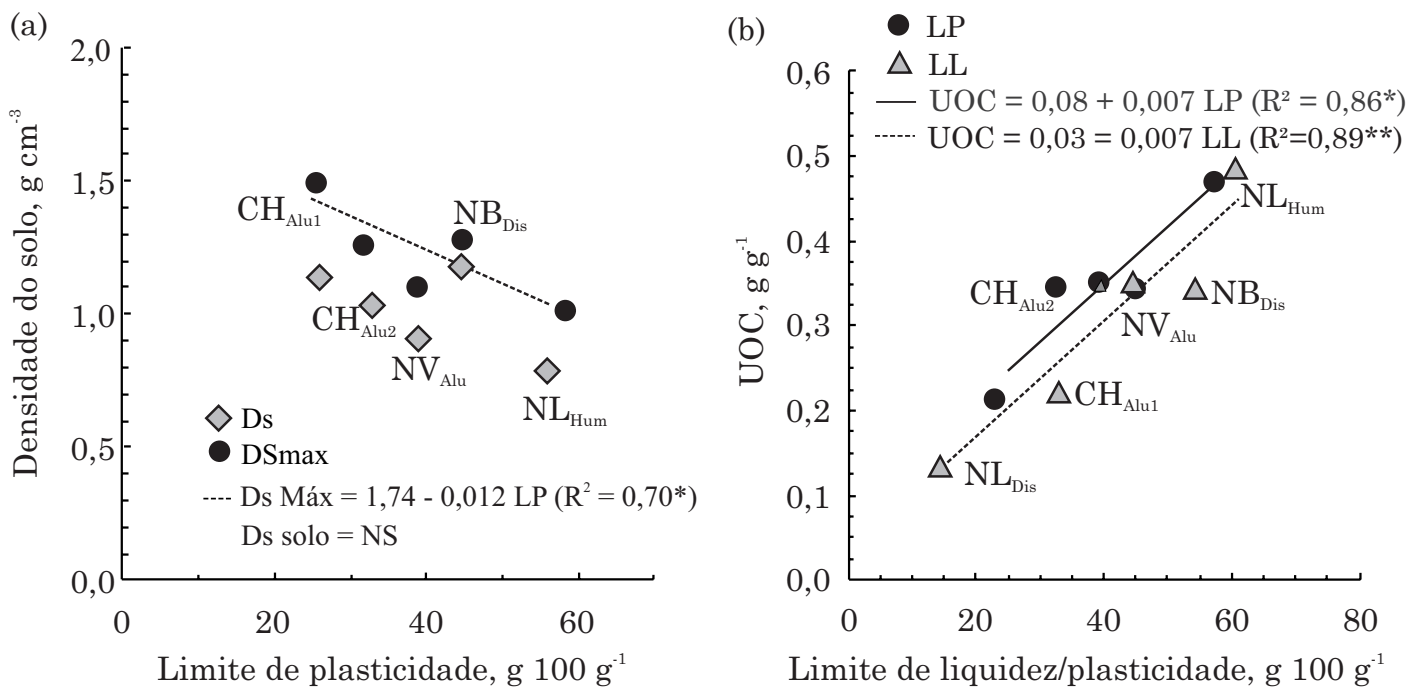

Limite de liquidez/plasticidade, g $100 \mathrm{~g}^{-1}$

Figura 5. Relação entre o limite de plasticidade e a densidade máxima e densidade do solo (a) e entre os limites de plasticidade e liquidez e a umidade ótima de compactação (b) no horizonte A de seis solos do

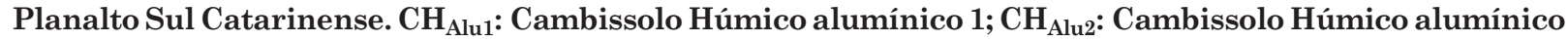
$2 ; \mathrm{NV}_{\mathrm{Alu}}$ : Nitossolo Vermelho alumínico; $\mathrm{NB}_{\mathrm{Dis}}$ : Nitossolo Bruno distrófico; $\mathrm{NL}_{\mathrm{Hum}}$ : Neossolo Litólico húmico, $\mathrm{NL}_{\text {Dis }}$ : Neossolo Litólico distrófico.*: significativo $(0,01<p<0,05) \mathrm{e}^{* * *}$ : significativo $(p<0,01)$ pelo teste $\mathrm{F}$.

(a)

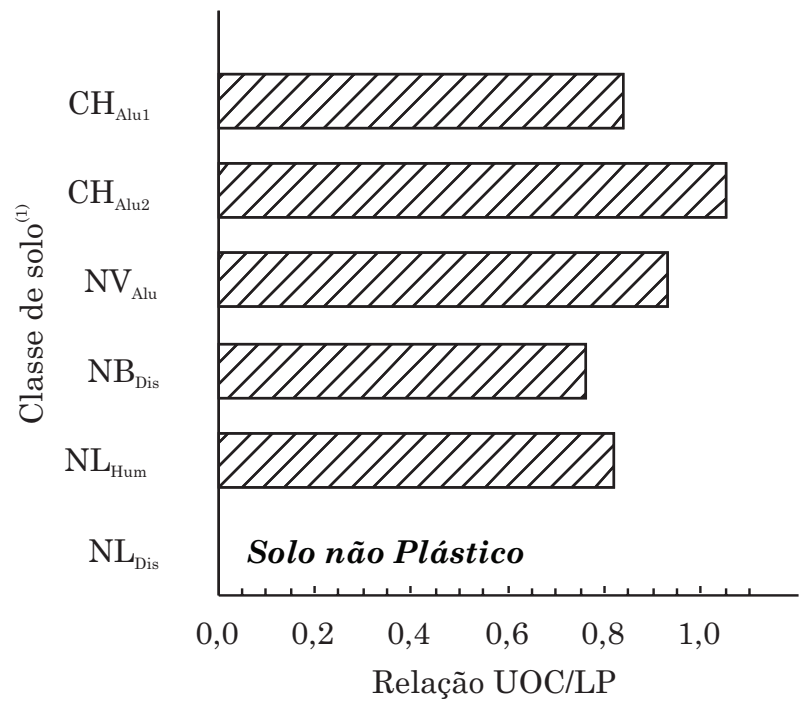

(b)

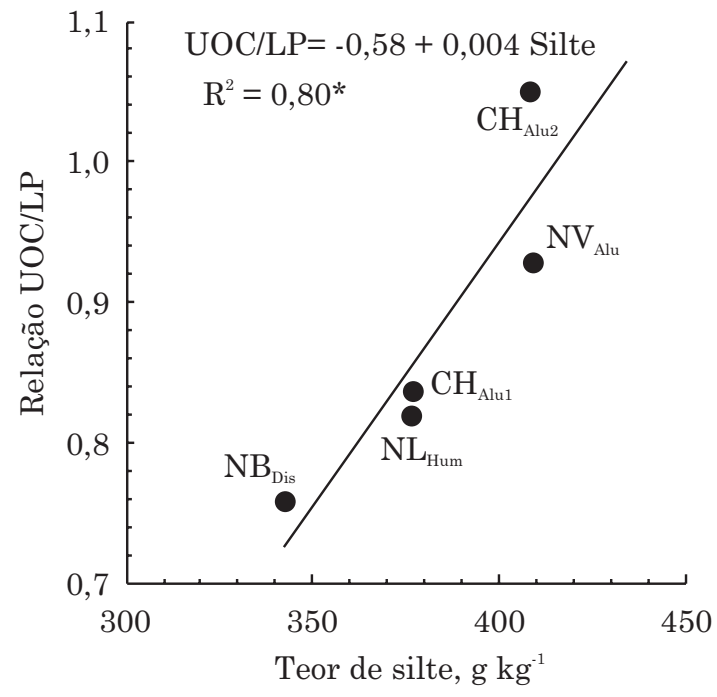

Figura 6. Relação entre umidade ótima de compactação e limite de plasticidade (UOC/LP) (a) e relação entre UOC/LP e o teor de silte (b) do horizonte A de seis solos do Planalto Sul Catarinense. ${ }^{(1)} \mathrm{CH}_{\mathrm{Alu} 1}$ : Cambissolo Húmico alumínico 1; $\mathrm{CH}_{\mathrm{Alu} 2}$ : Cambissolo Húmico alumínico 2; $\mathrm{NV}_{\mathrm{Alu}}$ : Nitossolo Vermelho alumínico; $\mathrm{NB}_{\text {Dis: }}$ : Nitossolo Bruno distrófico; $\mathrm{NL}_{\mathrm{Hum}}$ : Neossolo Litólico húmico, $\mathrm{NL}_{\mathrm{Dis}}$ : $\mathrm{Neossolo}$ Litólico distrófico. *: significativo $(0,01<\mathrm{p}<0,05)$ pelo teste $\mathrm{F}$. 
diferenciada em relação a solos de outros locais, o que pode ser uma consequência dos elevados teores de matéria orgânica e de silte desses solos.

A relação entre UOC/LP é utilizada como indicador da umidade ideal de manejo para uma maior desagregação do solo, em caso de revolvimento. A vantagem de usar a relação UOC/LP é que o LP é uma determinação que exige apenas a disponibilidade de uma placa de vidro fosco, uma estufa e uma balança. Entretanto, não é possível obter essa relação em solos arenosos, os quais não possuem limite de plasticidade, como foi o caso do NL distrófico.

O Nitossolo Bruno apresenta a menor relação UOC/ LP, o que indica que é o mais suscetível à compactação, pois o intervalo de umidade no qual o solo está friável se sobrepõe ao intervalo de umidade no qual o solo está mais suscetível à compactação. Por outro lado, o $\mathrm{CH}_{\mathrm{Alu} 2}$ é menos suscetível à compactação, pois a sua UOC é maior do que o seu LP.

\section{CONCLUSÕES}

1. A umidade ótima de compactação diminui nos solos mais arenosos, especialmente naqueles com predominância de areia fina, e aumenta naqueles com altos teores de argila ou carbono orgânico total e maiores limites de Atterberg.

2. A umidade ótima de compactação variou entre 0,76 e 1,05 vezes o limite de plasticidade, com relação direta com o teor de silte, indicando que a umidade ótima de compactação não pode ser avaliada pela determinação do limite de plasticidade do solo.

3. A densidade máxima de compactação aumenta em solos com o teor de areia total e areia fina e reduz em solos com maiores teores de argila e maiores limites de liquidez e de pegajosidade.

4. Os solos de altitude do Planalto Sul de SC têm relação UOC/LP diferente da de solos de outros locais, como consequência dos elevados teores de matéria orgânica e de silte desses solos.

\section{LITERATURA CITADA}

ALMEIDA, J.A. \& KAMPF, N. Caracterização mineralógica de Cambissolos derivados de rochas pelíticas nos patamares do Alto Itajaí e Planalto de Lages. R. Bras. Ci. Solo, 21:181190, 1997.

ASSOCIAÇÃO BRASILEIRA DE NORMAS TÉCNICAS ABNT. NBR 7182: Solo: Ensaio de compactação. Rio de Janeiro, 1986. 10p.

AMERICAN SOCIETY FOR TESTING AND MATERIALS ASTM. D2487-06. "Standard practice for classification of soils for engineering purposes (Unified Soil Classification System)". Washington, 2008.
BAUMGARTL, T. \& HORN, R. Effect of aggregate stability on soil compaction. Soil Tillage Res., 19:203-213, 1991.

BEUTLER, A.N.; CENTURION, J.F.; ROQUE, C.G. \& FERRAZ, M.V. Densidade relativa ótima de Latossolos Vermelhos para a produtividade de soja. R. Bras. Ci. Solo, 29:843849, 2005.

BENEZ, M.C. Dados e informações biofísicas da Unidade de Planejamento Regional Planalto Sul Catarinense - UPR 3. In: DUFLOTH, J.H.; CORTINA, N.; VEIGA, M. \& MIOR, L.C., eds. Estudos básicos regionais de Santa Catarina. Florianópolis, EPAGRI, 2005. CD-ROM.

BRAIDA, J.A.; REICHERT, J.M.; VEIGA, M. \& REINERT, D.J. Resíduos vegetais na superfície e carbono orgânico do solo e suas relações com a densidade máxima obtida no ensaio Proctor. R. Bras. Ci. Solo, 30:605-614, 2006.

BRAIDA, J.A.; REICHERT, J.M.; DALVAN, J.; REINERT., D.J. \& VEIGA, M. Teor de carbono orgânico e a susceptibilidade à compactação de um Nitossolo e um Argissolo. R. Bras. Eng. Agric. Amb., 14:131-139, 2010.

BUCKMAN, H.O. \& BRADY, N.C. Natureza e propriedade dos solos. 5.ed. Rio de Janeiro, Freitas Bastos, 1979. 647p.

CAPUTO, H.P. Mecânica dos solos e suas aplicações. 6.ed. Rio de Janeiro, Livros Técnicos e Científicos, 1987. 219p.

CARTER, M.R. Relative measures of soil bulk density to characterize compaction in tillage studies on fine sandy loams. Can. J. Soil Sci., 70:425-433, 1990.

CASAGRANDE, A. Classification and identification of soils. Am. Soc. Civil Eng., 113:901-930, 1948.

COMISSÃO DE QUÍMICA E FERTILIDADE DO SOLO CQFS-RS/SC. Manual de adubação e de calagem para os estados do Rio Grande do Sul e Santa Catarina. 10.ed. Porto Alegre, Sociedade Brasileira de Ciência do Solo/ Núcleo Regional Sul/UFRGS, 2004. 400p.

DALMOLIN, R.S.D.; GONÇALVES, C.N.; DICK, D.P.; KLAMT, E.; KNICKER, H. \& KÖGEL-KNABNER, I. Organic matter characteristics and distribution in Ferralsols profiles of a climosequence in Southern Brazil. Eur. J. Soil Sci., 57:644-654, 2006.

DIAS JUNIOR, M.S. \& MIRANDA, E.E.V. Comportamento da curva de compactação de cinco solos da região de Lavras (MG). Ci. Agrotec., 24:337-346, 2000.

DIAS JUNIOR, M.S. \& PIERCE, F.J. Revisão de literatura: O processo de compactação do solo e sua modelagem. R. Bras. Ci. Solo, 20:175-182, 1996.

EKWUE, E.J. \& STONE, R.J. Organic matter effects on the strength properties of compacted agricultural soils. Trans. Am. Soc. Agron. Eng., 38:357-365, 1995.

EKWUE, E.J. \& STONE, R.J. Density-moisture relations of some Trinidadian soils incorporated with sewage sludge. Trans. Am. Soc. Agron. Eng., 40:317-323, 1997. 
EMPRESA BRASILEIRA DE PESQUISA AGROPECUÁRIA . EMBRAPA. Manual de métodos de análise de solo. 2.ed. Rio de Janeiro, Serviço Nacional de Levantamento e Conservação de Solos, 1997. 212p.

EMPRESA BRASILEIRA DE PESQUISA AGROPECUÁRIA . EMBRAPA. Centro Nacional de Pesquisa de Solos. Sistema brasileiro de classificação de solos. 2.ed. Rio de Janeiro, Embrapa Solos, 2006. 306p.

FIGUEIREDO, L.H.A.; DIAS JUNIOR, M.S. \& FERREIRA, M.M. Umidade crítica de compactação e densidade do solo máxima em resposta a sistemas de manejo num Latossolo Roxo. R. Bras. Ci. Solo, 24:487-493, 2000.

GEE, G.W. \& BAUDER, J.W. Particle-size analysis. In: KLUTE, A., ed. Methods of soil analysis: Physical and mineralogical methods. 2.ed. Madison, American Society of Agronomy, 1986. Part 1. p.383-411.

GUBIANI, P.I.; REINERT, D.J. \& REICHERT, J.M. Método alternativo para a determinação da densidade de partícula do solo - exatidão, precisão e tempo de processamento. Ci. Rural, 36:664-668, 2006.

HÅKANSSON, I. A method for characterizing the state of compactness of the plough layer. Soil Tillage Res., 16:105$120,1990$.

HÅKANSSON, I. \& LIPIEC, J. A review of the usefulness of relative bulk density values in studies of soil structure and compaction. Soil Tillage Res., 53:71-85, 2000.

HILLEL, D. Environmental soil physics. New York, Academic Press, 1998. 771p.

KELLER, T. \& HÅKANSSON, I. Estimation of reference bulk density from soil particle size distribution and soil organic matter content. Geoderma, 154:398-406, 2010.

LIPIEC, J.; HÅKANSSON, I.; TARKIEWICZ, S. \& KOSSOWSKI, J. Soil physical properties and growth of spring barley as related to the degree of compactness of two soils. Soil Tillage Res., 19:307$317,1991$.

MARCOLIN, C.D. Propriedades físico-hídrico-mecânicas de solos sob plantio direto, na região de Passo Fundo - RS. Passo Fundo, Universidade de Passo Fundo, 2006. 92p. (Tese de Mestrado).

MARCOLIN, C.D. \& KLEIN, V.A. Determinação da densidade relativa do solo por uma função de pedotransferência para a densidade do solo máxima. Acta Sci. Agron., 33:349$354,2011$.
MEURER, E.J.; RHENHEIMER, D. \& BISSANI, C. Fenômenos de superfície. In: MEURER, E.J., ed. Fundamentos de química do solo. Porto Alegre, Genesis, 2000. 174p.

OJENIYI, S.O. \& DEXTER, A.R. Soil factors affecting the macrostructures produced by tillage. Trans. Am. Soc. Agron. Eng., 22:339-343, 1979.

OLIVEIRA, A.M.S. \& BRITO, S.N.A. Caracterização e classificação dos solos. In: PASTORE, E.L. \& FORTES, R.M., eds. Geologia de engenharia. São Paulo, ABGE, 1998. p.197-211.

PANDOLFO, C.; BRAGA, H.J.; SILVA JR, V.P.; MASSIGNAM, A.M.; PEREIRA, E.S.; THOMÉ, V.M.R. \& VALCI, F.V. Atlas climatológico digital do Estado de Santa Catarina. Florianópolis, EPAGRI, 2002. CD ROM.

REICHERT, J.M.; SUZUKI, L.E.A.S.; REINERT, D.J.; HORN, R. \& KANSSON, I.H. Reference bulk density and critical degree-of-compactness for no-till crop, production in subtropical highly weathered soils. Soil Tillage Res., 102:242-254, 2009.

SILVA, A.P.; LIBARDI, P.L. \& CAMARGO, O.A. Influência da compactação nas propriedades físicas de dois Latossolos. R. Bras. Ci. Solo, 10:91-95, 1986.

SKEMPTON, A.W. The colloidal "Activity" of clays. In: INTERNATIONAL CONFERENCE ON SOIL MECHANICS AND FOUNDATION ENGINEERING, 3., Zurich, 1953. Proceeding... Zurich, 1953. p.57-61.

STANCATI, G.; NOGUEIRA, J.B. \& VILAR, O.M. Ensaios de laboratórios em mecânica dos solos. São Carlos, Universidade de São Paulo, Escola de Engenharia de São Carlos, 1981. 208p.

STONE, R.J. \& EKWUE, E.I. Maximum bulk density achieved during soil compaction as effected by the incorporation of three organic materials. Trans. Am. Soc. Agron. Eng., 36:1713-1719, 1993.

SUZUKI, L.E.A.S.; REICHERT, J.M.; REINERT, D.J. \& LIMA, C.L.R. Grau de compactação, propriedades físicas e rendimento de culturas em Latossolo e Argissolo. Pesq. Agropec. Bras., 42:1159-1167, 2007.

TAYLOR, H.M. \& HENDERSON, D.W. Some effects of organic additives on compressibility of Yolo silt loam soil. Soil Sci., 88:101-106, 1959.

TEDESCO, M.J.; GIANELLO, C.; BISSANI, C.A.; BOHNEN, H. \& VOLKWEISS, S.J. Análise de solo, plantas e outros materiais. 2.ed. Porto Alegre, Universidade Federal do Rio Grande do Sul, 1995. 174p.

VARGAS, M. Solos porosos e colapsíveis. São Carlos, Departamento de Geotecnia - EESC - USP, 1993. 39p. (Apostila). 